\title{
EL PAPEL DE LA POLICÍA EN UNA SOCIEDAD DEMOCRÁTICA
}

\section{Gonzalo Jar Couselo}

Doctor en Ciencias Políticas

E-mail: gonzajar@orfila.mir.es

\begin{abstract}
RESUMEN
Desde un enfoque más próximo a lo histórico-político que a la tradicional visión jurídica que se ha venido utilizando en los todavía escasos estudios que sobre la Policía se han realizado en España, se pretende delimitar, a partir de un breve recorrido por lo que ha sido la evolución histórica de la misma, el papel que a dicha institución le puede corresponder en la sociedad del siglo XXI.
\end{abstract}

\section{ORIGEN Y EVOLUCIÓN DEL CONCEPTO DE POLICÍA}

Hablar de Policía significa remontarse a los orígenes de la constitución de los primeros núcleos de población organizada, como representación evidente de la autoridad ejercida por los que, en cada momento, detentaban el poder. Se puede decir, sin temor a equivocarse, que el servicio de policía es una actividad que, de una u otra manera, afecta a todos los ciudadanos en algún momento de su vida; de ahí que nadie ponga en duda la necesidad de su existencia, pues a todo Estado se le exige, por encima de cualquier otra consideración, que sea capaz de asegurar la tranquilidad del conjunto de los ciudadanos.

Aunque son muchas las definiciones que en torno al concepto policía circulan entre los estudiosos del tema, con el fin de no perderse en debates teóricos y lograr un mínimo acuerdo sobre la cuestión objeto de análisis, parece 
adecuado echar mano de la definición que la Grand Enciclopédie (1910) recoge: "No se conoce apenas sociedad un poco organizada sin que exista un poder de policía que asegure a sus miembros la seguridad interior, que reprima y prevenga los delitos contra las personas y propiedades y, por otra parte, asegure la obediencia a los representantes del Estado y la aplicación de las disposiciones dictadas por los jefes."

Si existe un acuerdo muy generalizado respecto del relevante papel que la Policía desempeña dentro de su respectivo sistema sociopolítico, como institución encargada de determinar los límites de la libertad — rasgo esencial de garantía de dicho sistema que, para Bayley (1985), constituye la "quintaesencia de la función gubernamentaln-.-, llama la atención la escasez de estudios dedicados a tales cuestiones, si se compara con los dedicados a instituciones como el Parlamento, el Ejército, el Gobierno o la Administración en general.

Para dicho autor, tres serían las razones de tal abandono. La primera, no haber considerado a la Policía como actor decisivo en los eventos históricos más trascendentales de la historia, al estimar los científicos sociales que se estaba ante actividades profesionales rutinarias de escaso prestigio, a diferencia de la imagen heroica con que se representaba a los militares; en ese sentido, el mismo Bayley justifica esa situación tanto en el sistema de reclutamiento de los policías entre las clases más bajas de la sociedad como en el uso de la violencia en conflictos internos, lo que le confiere un carácter más bien sórdido y poco honorable.

Las otras dos serían: una larga tradición de secreto en sus actuaciones -Lapierre (1973: 18) afirma que "la Policía está más dispuesta a recoger informaciones sobre otros grupos que a darlas sobre ella misma"-, considerada como una imprescindible necesidad funcional, y, por último, los juicios y reacciones que la misma genera ante la comunidad científica. Respecto a esta última cuestión hay que decir que los mismos suelen ser contradictorios, al estar condicionados tanto por sentimientos de afecto, más o menos sinceros o interesados, como por prejuicios ideológicos o partidistas, lo que provoca enfoques ya sean apologéticos o descalificadores, lo que, en uno y otro caso, impide la necesaria neutralidad que debe exigirse a todo análisis que se precie de riguroso.

$\mathrm{Si}$ bien es cierto que el trabajo de los investigadores suele generar en los policías sospechas de intenciones perversas e incluso subversivas, aquéllos recelan por sistema de las informaciones que éstos les facilitan, ya que, en el caso de asumir los presupuestos oficiales, podrían ser considerados como cómplices de las estructuras de poder. Por todo ello, pronunciarse y, en mayor medida, dedicarse de manera específica a cuestiones relacionadas con la Policía resulta no sólo incómodo, sino de dudosa rentabilidad dentro de los ámbitos institucionales públicos, llegando todavía a provocar un no indisimulado malestar en la mayoría de círculos universitarios.

El enfoque utilizado aquí será el histórico-político, en la medida que se tratará de analizar la vinculación que, a lo largo de la no muy dilatada historia de la Policía —entendida en el sentido moderno del término-, se ha produci- 
do entre esta institución y el poder político. De cara a rebuscar en sus orígenes, lo primero que hay que constatar es que la organización y funciones de la Policía han estado indisolublemente vinculadas a las características sociopolíticas y culturales de la respectiva comunidad; de ahí que su evolución institucional debe analizarse a la luz de los cambios que se producen en los correspondientes modelos sociales en que se integran. El mismo Bayley recuerda que «el volumen, la organización y el funcionamiento de su aparato policial son elementos que no deberian olvidarse cuando se comparan sistemas políticos».

Históricamente se ha concebido siempre a la Policía como una correa de transmisión del orden constituido; de ahí que la estructura organizativa y funcional de la misma implicase el mantenimiento de férreas relaciones internas militarizadas que permitían un mejor control sobre los ciudadanos. Como afirma Martín (1991: 15), "la simbiosis entre la Policía y el poder perdurará a lo largo de la historia", no sólo porque los diferentes gobiernos la utilicen en favor de sus intereses, sino que la propia institución asumirá como función primordial propia la defensa del orden instituido; de ahí la frecuente aparición y desaparición de Cuerpos a causa de los simultáneos cambios gubernamentales.

Si se admite que la Policía es uno de los elementos que configuran la organización social, y por tanto su actuación ha de encaminarse a la consecución de los objetivos que ésta establezca, es natural que el modelo de Policía se viese sometido a los avatares políticos que se derivasen de las permanentes confrontaciones entre tendencias que iban a ir surgiendo: mundo rural/mundo urbano; absolutismo/liberalismo; militarismo/civilismo o centralismo/municipalismo.

El mismo Martín entiende que, tal y como se conoce en la actualidad, los orígenes de la Policía son bastante recientes, aunque no los de las funciones policiales. Así, los primeros Cuerpos eran instituciones sin estabilidad temporal, escasamente profesionalizados y confundidos frecuentemente con los típicamente militares, hasta el punto que con frecuencia era el mismo Ejército el que intervenía directamente. La militarización iba a ser una constante en la gran mayoría de países, tendencia que, en muchos de ellos, perduraría hasta el siglo $\mathrm{XX}$, momento en el que se produce un movimiento de desmilitarización que se hará más o menos evidente en función de las características del respectivo régimen.

Según Ballbé (1983: 28), el Estado absolutista estaba caracterizado por la concentración de poderes, incluido el judicial, con una "decisiva y permanente presencia de instituciones militares en el ordenamiento y en la praxis del orden público, de la organización policial y del régimen judicial", de tal manera que la autoridad militar concentraba las competencias en las cuestiones de Policía y orden público y el mando directo de la fuerza pública de intervención interior.

Los riesgos que se derivaban eran evidentes, pues si, como opina López Garrido (1987: 28), la confusión entre función militar y función policial era patente, así como entre mantenimiento del orden interno y defensa de las fronteras exteriores, la consecuencia inevitable era que, en úlrima instancia, acaba imponiéndose siempre la idea militar de eliminación física del enemigo 
sobre la moderna idea policial de prevención del delito y captura del delincuente.

La concepción ilustrada (siglo XVIII) supuso, respecto al pasado, un salto cualitativamente importante, pues entendía el progreso como el avance de la conciencia y la práctica de la libertad, al que, en una concepción más economicista, se identificaba con el desarrollo de la ciencia y de la técnica aplicadas, planteamientos que no tenían por qué ser excluyentes, en la medida que el desarrollo económico posibilitaba a menudo mayores espacios de libertad, sin que nunca pudiese primar la vertiente económica sobre la de la libertad.

En esa época en España, los incipientes Cuerpos de seguridad se dedican preferentemente a finalidades represoras de desórdenes públicos, dejando en un segundo plano la labor investigadora de la delincuencia común o la asistencial, mientras el Ejército sigue siendo el elemento básico del modelo de seguridad. Una variante de este modelo -la denominada doctrina Mansfield- estuvo vigente a lo largo de ese siglo en el área anglosajona, basada en la utilización extraordinaria del Ejército en el mantenimiento del orden público, siempre sometido a las órdenes de la autoridad civil que solicitase la intervención, y la creación de unas fuerzas civiles locales para el desarrollo de funciones policiales.

En relación con esta última cuestión se constata cómo, desde la aparición en Europa de los modernos Estados, a diferencia de lo que ocurriría en Inglaterra, tradicionalmente los diferentes gobiernos no permitieron desarrollar modelos de Policía de ámbito local. A lo largo de este período, y debido a la ausencia de objetivos claros, no existe planificación alguna y sí una constante indefinición de funciones. A falta de una verdadera profesionalización, la Policía se ve convertida casi en exclusiva en un aparato de represión.

Cuando la Revolución francesa consagra el principio fundamental de que la ley es la garantía de los derechos del ciudadano se pone fin al despotismo, incluida su variante más moderna de despotismo ilustrado, $y$, al menos en Francia, en palabras de Ballbé (1983: 40), se consagra el «acta de defunción del Antiguo Régimen". En el artículo 12 de la Declaración de Derechos del Hombre y del Ciudadano se establece que: "La garantía de los derechos del hombre y del ciudadano necesita de una fuerza puiblica. Esta fuerza se instituye, por tanto, para beneficio de todos y no para la utilidad de aquellos que la tienen a su cargo".

El profesor Loubet reflexiona en torno a cómo, en el momento en que se percibe la necesidad de crear esa fuerza pública que ampare al nuevo poder político, se plantean una serie de cuestiones que han seguido manteniéndose hasta la actualidad y que constituyen la esencia de la misma: ¿En qué consiste? ¿A quién pertenece? ¿Quién la dirige? ¿Cuándo debe emplearse? ¿Con qué procedimientos? ¿Qué tipo de controles se establecerán?

El liberalismo imperante a lo largo de todo el siglo XIX servirá para confrontar los dos modelos más importantes de Policía: el anglosajón (inglés) y el continental (francés). El primero, también denominado por Loubet (1992: 25) Policía del Pueblo, surge de demandas fruto de una autorregulación social, y el segundo, Policía del Principe, en el que priman consideraciones políticas para 
la construcción del Estado. Dicho autor establece con los dos modelos una relación entre legitimidad del sistema político y recurso a la coacción, de tal manera que si al centralizado, militarizado y alejado de la sociedad le corresponde un menor nivel de apoyos y legitimidad y más empleo de la fuerza física, al descentralizado, civil y próximo al ciudadano se le atribuye un mayor nivel de apoyos y legitimidad y menor recurso a la coacción.

El modelo continental europeo se caracterizaba por estructuras organizativas militarizadas, despliegue en forma de tela de araña a lo ancho de todo el territorio, fuerte centralización con un sistema de información a nivel nacional y distante de la sociedad a la que tenía que controlar, cuyo paradigma será el creador de la Policía francesa, Fouché, expandida a todo el territorio y estatalizada, a partir de 1880 , con los omnipresentes comisarios generales a la cabeza. Es en base a esos presupuestos cómo, en palabras de López Garrido (1987: 41), "la policía deviene puro medio de gobierno".

En el caso español —variante de este último-, a la hora de optar entre autoridad y libertad, se decantó indiscutiblemente por la primera; de ahí que Ballbé (1983: 49) lo considere como un "liberalismo de corte militarista". La Constitución de 1812 contiene dos rasgos básicos y característicos del mismo: ausencia de una amplia declaración de derechos y libertades y especial regulación del orden público, de la Administración encargada de mantenerlo y de su relación con el Derecho militar.

Frente a ese modelo, el anglosajón establece, en base a una larga tradición inglesa anterior incluso al siglo XVII contraria a la aplicación del Derecho militar a los civiles, una tajante separación entre Ejército y Policía y vinculación al poder local. En 1829, R. Peel funda el Cuerpo de Policía Civil (Policía Metropolitana de Londres), que consagra el apartamiento definitivo de la fuerza militar en el orden interno; además, se trataba de huir del modelo francés, al considerar que, desde la época Fouché, la Policía en ese país venía jugando un papel político determinante. Ante los buenos resultados de la administración policial instaurada, se hace extensiva a todo el país a través de la Ley de Corporaciones Municipales (1835) y, posteriormente, con la Ley de Policía de los Condados (1839), en las que se exige mantener una fuerza policial retribuida, con agentes sin armas (sólo una porra) y principalmente en funciones de prevención.

La Policía no se modelaba como un cuerpo separado de la sociedad, sino que se instauraba sobre una base de cuerpo local, actuando la Administración central a través de la Policía local, que recibe las órdenes de las autoridades locales, más conocedoras del entorno y de sus especiales características. A lo largo de todo ese siglo, el empleo de militares en la resolución de conflictos internos se hace cada vez menos importante. La excepción a esa tendencia se produce en 1880, cuando, para combatir el terrorismo irlandés y anarquista, el Gobierno británico se ve obligado a crear una Policía de investigación, la Special Branch. 


\section{LA POLICÍA Y EL SISTEMA POLÍTICO}

Una vez concluido ese breve, pero necesario, recorrido histórico por los orígenes de la Policía, llega el momento de entrar de lleno en el objeto de este trabajo - -el papel de la Policía en un sistema democrático--, para lo cual se describirá previamente de manera somera cómo actúa ésta en un sistema dictatorial o autoritario y, lo que parece más interesante, cómo se produce la transición hasta una sociedad democrática.

En los regímenes autoritarios, la Policía tiende a adoptar organizaciones de tipo piramidal, central y jerarquizado, con procesos de formación y socialización inspirados en principios militares como obediencia, jerarquía o disciplina, pues para llevar a cabo el necesario control político y reprimir las disidencias debe estar lo más lejos posible de la población para evitar contagios. Este tipo de sistemas se caracteriza por una gran ambigüedad funcional, en la que predominan las tareas encaminadas al control de actividades político-sociales, aun cuando en las que se manifiesta con mayor rigor es en las de mantenimiento del orden público.

Ese predominio de las motivaciones políticas sobre las societales o comunitarias obliga a que el poder político le conceda una extraordinaria importancia al policía como agente de información --Loubet (1992: 42) considera que es la única fuente "objetiva", capaz de influir y condicionar las decisiones del poder político, ya sea ocultando o difundiendo información interesada-, en la medida que actuará como agente de transmisión de demandas societales para el sistema político; de ahí la tendencia a multiplicar el número de servicios de información para no quedar a merced de una sola fuente y suplir las carencias que puedan presentar alguno de ellos. La importancia de esa función se resume en reflexiones como las de Saussaies (1972: 8) — "una Policía no informada es una Policía paralizada"- o Gleizal (1985): "Antes de poder, la Policia debe saber".

Respecto al tan debatido tema de la identificación de este tipo de regímenes con la pluralidad o no de Cuerpos -es indudable que con varios se consigue un fraccionamiento del poder y de las influencias corporativas--, algunos autores estiman que los poderes absolutos prefieren contar con un único aparato de seguridad imbuido de los principios que inspiran el régimen — fidelidad que se consigue a través de todo tipo de privilegios-, sin que el poder que se le otorga corra el riesgo de diluirse o incluso volverse contra el mismo. Los defensores de la teoría de la guerra de policias admiten que tal sistema genera disfunciones pero, también, una sana competencia entre ellas, al tiempo que evita cualquier clase de pretensión contraria a los principios del sistema. En realidad, la experiencia dice que se está más ante una cuestión de tradición histórica que de teoría política.

Otro rasgo característico es la militarización del sistema policial - ya sea en sus estructuras orgánicas como en los principios funcionales y el estatuto de sus agentes-, lo que, a través de la permanente ósmosis entre los mundos 
militar y policial - sobre todo en el frecuente trasvase de personal militar hacia los puestos de mando y dirección-, permite asegurar una mayor lealtad al sistema político. En ese sentido, las instalaciones donde llegan a convivir agentes y familias, si bien permite evitar que se vean sometidos a presiones que puedan comprometer su independencia, con lo que el sistema político consigue al mismo tiempo que la Policía le siga manteniendo su apoyo, genera un aislamiento social poco grato a los principios democráticos y a la idea del policía-ciudadano. Tal planteamiento no parece ser el más adecuado para llevar a cabo las clásicas funciones de investigación o de seguridad pública.

Esa situación de partida es la que dificulta enormemente el paso de un modelo de Policía en un sistema autoritario a otro democrático, razón por la que es conveniente someterse al paso previo de una transición, a cuyo fin lo primero que debe producirse es una transformación paralela entre sistema políticoconstitucional y sistema policial. La actuación de éste no puede ser considerada de forma aislada, sino dentro de un proceso mucho más amplio en el que participen múltiples y diversas instituciones, con objeto de que las soluciones tengan vocación de permanencia y no sean el resultado de intereses coyunturales.

Si bien el modelo militar de organización servía para garantizar la lealtad política de la Policía, no era el más adecuado para garantizar el libre y pacífico ejercicio de derechos y libertades, por lo cual se hace necesario crear un clima general de orden, tolerancia y paz que convierta a la Policía en un elemento básico del conjunto homogéneo en el que sea posible conseguir mayores cotas de eficiencia con un menor riesgo para las libertades.

Para Barletta (1992: 163), la imagen tradicional de la Policía había sido, durante mucho tiempo, la de "brazo armado del poder político, ejecutora y realizadora de todas las opresiones y represiones", cuyos miembros - gente ruda, sin preparación y mal pagada - vivían de espaldas a la sociedad, imagen que, al menos en Europa occidental y debido a la evolución sociopolítica, se relacionaba cada vez más con el pasado. Para él, ese cambio se debía fundamentalmente a dos importantes hechos culturales: la toma de conciencia por parte de los propios policías del cumplimiento de sus derechos y obligaciones, y de la comunidad y opinión pública que les atribuyen un nuevo rol en la organización del Estado y de la sociedad.

Si se concuerda con Szabo (1982) en que ues la sociedad la que modela a la policía y no al revés; sólo una sociedad civilizada puede tener el derecho y el privilegio de una policía civilizada", tendrá razón Martín cuando advierte que, si se produce la transición de un sistema autoritario a otro democrático sin introducir cambios profundos en el aparato policial, pueden surgir graves contradicciones y los costes pueden ser elevados. Hay que tener en cuenta que, en estos procesos, las actitudes largamente arraigadas no se modifican por la sola publicación de nuevas normas; en ese sentido, puede decirse que «aunque cambien las formas, la filosofia permanece".

Al final, pues, si de lo que se trata es de cambiar la filosofía, parece imprescindible concentrar todos los esfuerzos en conseguir la transición deseada por medio 
de la transmisión de las ideas que permitan llevar a buen término el proceso. No es de extrañar, entonces, que los analistas coincidan en atribuir una importancia capital al tema de la formación — nótese que esto no resulta tan fácil ya que, sobre todo en épocas de crisis económica, es uno de los capítulos que primero se reducen-, teniendo en cuenta que los agentes más veteranos son los que peor se adaptan al cambio, al dudar de que el sistema democrático les permita disfrutar del teórico prestigio y autoridad que tenían en el régimen autoritario.

Como no existe nada más pedagógico que la descripción de la realidad, parece oportuno echar mano de la experiencia que H. U. Herzberg (1994), policía de la RFA que se hizo cargo del proceso de transformación de la Policía del Estado de Sajonia (en la extinta RDA) tras la caída del muro de Berlín, algo que considera mucho más fácil de decir que de poner en práctica. Su primera constatación fue que las estructuras existentes en la antigua Policía popular no respondían de ninguna manera a las exigencias de una Policía democrática, toda vez que su imagen estaba caracterizada por su relación con el Estado de partido único socialista, en la medida que era el brazo armado más visible del sistema, con una fuerte orientación militar y que aparentaba un gran poder e influencia, pero que, en todo caso, sus actuaciones dependían siempre de las decisiones que se tomaban en el partido gobernante.

Como es lógico suponer, su formación estaba fuertemente ideologizada y con altas dosis de especialización, al permanecer de por vida en un tipo concreto de tarea, frente a una visión más generalista del policía occidental. Mientras en una democracia la imagen ideal del policía se caracteriza por ser un funcionario orientado hacia la justicia y la ley, que actúa bajo su propia responsabilidad, en la RDA sólo actuaba bajo instrucciones de sus superiores, sin ninguna responsabilidad sobre las consecuencias que se pudiesen derivar de sus decisiones. En el caso de la Stasi - agencia de seguridad estatal- no se cuestionaban conceptos como justicia y ley, constituyendo una estructura de información interna y externa que llegó a ser vista como "un Estado dentro del Estado".

Al tratar de cumplir con su tarea de garantizar la «tranquilidad y el orden» satisfacía los intereses de una parte de la población pero, al mismo tiempo, transmitía una imagen negativa entre los ciudadanos con ansias de libertad. En 1989, coincidiendo con los últimos estertores del régimen, la Policía se ve obligada a intervenir con extrema dureza para reprimir a la muchedumbre insatisfecha que todos los lunes se congregaba en manifestaciones multitudinarias para pedir la caída del régimen, lo que provocaría una reacción de desprecio y odio en el momento de la reunificación y que los agentes se viesen sometidos a múltiples acosos.

Uno de los problemas que condicionaron el ritmo de la transición era que en el momento de la reunificación se produce un notable incremento de las tasas de delincuencia, al mismo tiempo que los agentes se sentían especialmente preocupados por la seguridad en que habían quedado, abandonados y sin directrices concretas de actuación, ya que ni siquiera el personal directivo tenía muy claro lo que debía hacer. La realidad era que "nadie les había preparado para su tarea, función o lugar en un Estado democrático". Ésas eran algunas de 
las causas por las que la nueva organización sólo podía ser llevada a cabo por funcionarios occidentales, con experiencia y conocimientos adecuados a la nueva situación, pero siempre dentro de un marco de colaboración con el personal existente, a fin de generar el necesario clima de confianza.

En base a todo ello, los principales puntos establecidos para la reforma serían, en primer lugar, proceder a una adecuada selección de personal - de 16.000 agentes en el momento de la reunificación se pasaría a 11.000 -, en base a las siguientes razones: a) transferencia de muchas de las funciones que venían realizando, no especialmente policiales, a otros órganos de la Administración especializados en esas cuestiones (guardas jurados, vigilantes de prisiones, pasaportes, etc.); b) abandono de muchos altos cargos que previeron los cambios que se iban a producir, así como otros que, voluntariamente, optaron por incorporarse a sectores de la economía liberal, hasta entonces desconocidos para ellos, y c) aprovechar, sobre todo los de más edad, la posibilidad de prejubilación que se les otorgaba.

Además, para hacer frente a las demandas ciudadanas y sobre todo políticas, se puso en marcha lo que se denominó Acción de comprobación, mediante la cual se estudiaban las posibles vinculaciones políticas del personal y su nivel de colaboración con el Ministerio de Seguridad Estatal —del que dependía la Stasi-, a través de encuestas y peticiones de informes a la constituida Autoridad Gauck, encargada de administrar la herencia de dicho Ministerio, de tal manera que en la nueva Policía no podría integrarse ninguna persona con vinculaciones directas con dicha estructura.

El segundo esfuerzo iría dirigido a dotarlos de un nuevo equipamiento, la primera de cuyas medidas fue vestirlos con el mismo uniforme que el de todos los Estados de la RFA, a fin de transmitir a los ciudadanos el nuevo papel que iban a desempeñar. Además, se le facilitaría material adecuado a las necesidades de una Policía moderna: vehículos, equipos de protección y armamento, tratamiento científico de los problemas del tráfico e investigación criminal, uniformidad para cada tipo de tarea, sistemas de transmisiones y tratamiento de datos, nuevas y mejores dependencias, con lo que se produjo una espectacular transformación tanto desde el punto de vista material como funcional. A tal fin, fue necesario incrementar de manera notable los presupuestos policiales, tanto de personal como de inversiones.

En línea con la tradición democrática del Derecho policial de la RFA, se procede a la aprobación de la Ley de Policía de 1991, en la que se tienen en cuenta los intereses de los ciudadanos y otorga a los funcionarios las facultades necesarias para el cumplimiento de su misión, tratando de conseguir una «óptima relación entre policía y ciudadanos". De inmediato se afronta, también, el establecimiento de una organización adecuada a las nuevas estructuras administrativas y necesidades sociales, a raíz de lo cual se produjeron algunos descensos de grado, ya que las nuevas responsabilidades y el ámbito funcional no se correspondían con las de la Policía popular y hacía imposible la transferencia automática de niveles. 
Todo esto exige, como ya se dijo anteriormente, la puesta en marcha de urgentes procesos de formación, ya que el conocimiento y aplicación de la nueva normativa legal exigía inmediatos reciclajes de los antiguos agentes, apenas motivados y con escaso sentido de la responsabilidad. Para ello, se llevaron a cabo intercambios con otros Estados federales, lo que supuso un inevitable esfuerzo, en la medida que significaba detraer numerosos efectivos de los que tenían que prestar servicio en la calle, conseguir un mayor rendimiento de los presentes, así como una cierta comprensión de la sociedad. De esta manera, se elevó notablemente el nivel cultural y profesional de los agentes.

Como medida complementaria de las anteriores, no quedaba más remedio que establecer métodos de selección que permitiesen incorporar un abanico de agentes que fuese representativo de la nueva sociedad, así como modalidades de dirección adaptadas a la cultura institucional que se estaba implantando, todo ello con el fin de conseguir mejores niveles de eficiencia en la investigación de delitos, sobre todo en algunas modalidades hasta entonces inéditas en la RDA —narcotráfico y delincuencia organizada-, algunas de tanta relevancia política como los actos de violencia provenientes de la extrema derecha, en la medida que existían sospechas de cierta connivencia institucional con la misma.

Retomando el análisis teórico sobre lo que supone, desde el punto de vista de la institución policial, pasar de la dictadura a la democracia, convendría detenerse en torno a la confrontación de los conceptos orden público y seguridad ciudadana, ya que tal debate puede ser suficientemente esclarecedor de cara al objeto que aquí se analiza. La primera constatación es que se trata de dos concepciones bien diferentes a la hora de entender la función policial, pues si el primero lo que persigue es garantizar el orden previamente establecido desde los órganos de poder -implica certeza, represión y distanciamiento-, con el segundo enfoque se busca garantizar los derechos y libertades de los ciudadanos y su convivencia pacífica, dentro de un marco de incertidumbre, prevención y proximidad. En cualquier caso, hay que reconocer que existe una larga tradición histórica basada más en el primero de los enfoques que en el segundo, que no dejará de tener influencia incluso cuando se funciona dentro de éste.

López Garrido (1987: 7) sitúa el origen de la noción jurídica de orden público en el Código Civil napoleónico, cuyo objetivo era impedir que los pactos entre particulares atentasen contra los principios esenciales del nuevo orden político-social. El orden público era fundamento de poderes explícitos e implícitos y, en definitiva, la "cláusula de cierre» última del sistema autoritario. Para dicho autor, los Cuerpos de Policía, fuertemente militarizados, han sido los administradores de esa idea de orden público, hasta el punto de llegar a identificarse terminológicamente. Al referirse a la crisis de dicho concepto echa mano de Volpi, para quien el mantenimiento a ultranza del orden social vigente y del statu quo deja de ser un bien supremo cuya defensa pueda justificar el sacrificio de las libertades fundamentales, pues éstas deben ser siempre «el primer valor a proteger".

En la misma línea, Loubet (1996) estima que mientras el primero prima la 
protección del orden político, el segundo pone más el acento en la asistencia prestada a la comunidad, lo que no impide que, en muchos casos, coincidan ambas finalidades. Para él, los conceptos de orden público o mantenimiento del orden son típicamente europeos, más en concreto franceses, pero con menor trascendencia en los del área anglosajona, razón por la que éstos no llegan a entender demasiado bien la existencia de unidades específicas dedicadas a estas tareas.

Si los sucesos más importantes de la historia de un país suelen estar condicionados por los correspondientes problemas de mantenimiento del orden, en la medida que "detrás del orden público lo que está es el conjunto del orden político-social", parece claro que el análisis de los modos de intervención, basados en el empleo mínimo de la fuerza, vinculan esta evolución con los cambios sociopolíticos más profundos, como la democratización de las sociedades occidentales y la tendencia a largo plazo de la pacificación de las relaciones sociales.

Evoca cómo en Francia, entre 1900-10, se produjeron 30 muertos en conflictos de orden público a causa de la intervención del Ejército, lo que obligaría a replantearse el modelo tradicional existente hasta entonces. Relevantes fueron los tumultos vitivinícolas del Sur (1907), en los que los soldados del regimiento encargado de enfrentarse a los alborotadores se negaron a intervenir, dado que la mayoría eran originarios de dicha región. En realidad, el verdadero problema era que ni la Gendarmería ni las Policías urbanas disponían de medios para hacer frente a ese tipo de misiones; de ahí la necesidad de disponer de fuerzas móviles — que evitasen solidaridades locales-, profesionales y especializadas.

En 1918, tras la I Guerra Mundial y para hacer frente a numerosos tumultos, se ve claro que el Ejército, que durante cuatro años ha encarnado la idea de unidad nacional, no debe seguir asumiendo dicha función, razón por la que, en 1921, se procederá a la creación de los primeros Pelotones de Gendarmería Móvil y, en 1926, a la de la Guardia Republicana Móvil. Posterior sería la constitución de las Compañías Republicanas de Seguridad (CRS), en 1944, dentro de la Policía Nacional, que se había fundado en 1941.

Con tales decisiones se pretendía permitir las denominadas situaciones de "desorden legítimo", en las que los ciudadanos puedan expresar sus discrepancias con el sistema sin que peligre su integridad y que el resto de la ciudadanía pueda seguir ejerciendo sus derechos y libertades. Además, con el empleo de unidades ajenas al lugar de actuación se evitaba comprometer a los agentes destinados en el mismo. A modo de ejercicio teórico-comparativo, podría ser interesante establecer un paralelismo entre este proceso y el español, toda vez que, hasta 1978, dichos modelos de Policía eran muy semejantes. En todo caso, y como resumen de esta primera parte del análisis, cabría concluir afirmando que el paso de uno a otro concepto implica una visión diferente de la propia Policía, pues frente a la consideración de súbditos que se otorga en una dictadura, en la democracia se goza de la de ciudadanos, en la medida que es necesario subordinar los intereses del aparato policial, y sus agentes, al interés general. 
Se entraría, así, en el debate más actual que resulta de confrontar los conceptos libertad y seguridad, el cual, por cierto, ha sido y es objeto de permanente manipulación, pues lo primero que habría que determinar es el verdadero significado de términos como seguridad, paz u orden. En ese sentido, es sumamente aleccionadora la ya clásica definición que del último de estos conceptos dio Ortega y Gasset, cuando consideraba que el orden "no es una presión que desde fuera se ejerce sobre la sociedad, sino un equilibrio que se suscita en su interior».

Al objeto de clarificar en lo posible dicha manipulación, convendría distinguir entre lo que se considera inseguridad percibida o real y, dentro de ésta, diferenciar la que se produce de la que se recoge en las estadísticas oficiales - habitualmente manipuladas por causas de muy diversa índole: ya sea para demostrar altos niveles de eficacia o, por el contrario, para reclamar de los responsables políticos mejoras en la dotación de medios o reformas legislativas-, algo realmente importante pues resulta en extremo difícil no sólo distinguirlas, sino combatirlas de manera eficaz; en especial la primera de ellas, debido a su fuerte carga de subjetividad.

Además, cabria hablar, también, de un tipo específico de inseguridad, la institucional, entendiendo por tal la que tiene su origen en las consecuencias que se derivan de las decisiones adoptadas en instituciones oficiales de la Administración -en este caso la Policía-, ya sea porque no actúa con el rigor y contundencia que de ella se espera o porque se excede en el uso de sus atribuciones coactivas. Como asegura el profesor González Ballesteros, "el caso más peligroso de intromisión en la vida intima de los ciudadanos es el que ejerce el Estado», en tanto el periodista J. L. Cebrián afirmaba, en un Seminario Internacional sobre Policía, Justicia y Sociedad, celebrado en Sevilla en 1985, que "desmoraliza más a las fuerzas de seguridad la justificación de sus abusos que la represión de los mismos", cuestión ésta de tanta actualidad en estos momentos en España.

Frente a las tesis más conservadoras que prefieren la injusticia al desorden, hay que reclamar la existencia de garantías que permitan conciliar justicia y orden; es decir, asegurar el ejercicio de derechos y libertades de los ciudadanos con la represión de las conductas que atenten contra su seguridad. Existe una tradición histórica que atribuye a los regímenes democráticos una cierta debilidad a la hora de mantener el orden, llegando incluso a afirmar que el orden público ha sido el talón de Aquiles de los gobiernos de izquierda; de ahí que, llegados al poder, muchos de ellos hubiesen tenido que poner en práctica politicas de seguridad más duras incluso que las de los conservadores.

A propósito del debate que originó la elaboración de la Ley de Seguridad Ciudadana (1991-92), el entonces Defensor del Pueblo, A. Gil-Robles, decía que, en ocasiones, se trata de crear un clima social de inquietud -amenazas terroristas, racismo, inmigración clandestina, etc.- en virtud del cual el principio de seguridad ciudadana dañe o haga desaparecer el de libertad individual, advirtiendo que cualquier limitación de la libertad debe hacerse respetando la Constitución democrática, pues «los ciudadanos no pueden quedar inermes ante los errores o posibles abusos de las Fuerzas de Seguridad". 
Lo que sí es cierto es que la información de la que dispone la Policía es un elemento que hay que tener siempre presente, pues los riesgos que se derivan del concepto Estado policía no son exclusivos de los regímenes autoritarios, aunque en ellos sean, evidentemente, mayores. En los años cincuenta, la filosofía crítica ya advertía sobre los riesgos de que las sociedades modernas llegasen a ser totalmente administradas y dirigidas a través de la tecnología, lo que está planteando una cierta contradicción, pues si, por un lado, los ciudadanos son cada vez más libres desde el punto de vista legal, en la práctica se ven sometidos a mayores controles de todo tipo, en especial los que se derivan de la utilización de medios informáticos y que lleva a algunos a hablar de totalitarismo cibernético, razón por la que todos los países democráticos promulgan leyes que limitan y controlan su empleo.

Existe una teoría según la cual la democracia lleva consigo un incremento notable de los niveles de delincuencia, tanto en volumen como en gravedad, en tanto que en los regímenes autoritarios ocurriría lo contrario, al ser mayor el temor a la represión. Hay que denunciar la falsedad de tal planteamiento, toda vez que está demostrado que son múltiples los factores que influyen, ya sean de orden estructural - transformaciones institucionales y de sistemas de vida social- o coyuntural, debido a los desajustes que se produzcan en dicho sistema, tales como desempleo, falta de equipamientos, etc.; por cierto, son mucho más difíciles de atacar las consecuencias que se derivan de los primeros que las de estos últimos. Cuando esas acusaciones provienen del ámbito policial, suele tratarse de un pretexto para encubrir las carencias y falta de eficiencia de los Cuerpos de Seguridad para hacer frente a sus propias responsabilidades.

En todo caso, tal y como planteaba E. Larraya (El País, 6-IV-84), la democracia no tiene por qué generar un debilitamiento del principio de autoridad y, en consecuencia, un incremento de la inseguridad, básicamente por dos razones: la primera tendría que ver con la necesidad ya apuntada de tomar en consideración los elementos estructurales y coyunturales a la hora de analizar las estadísticas y, en segundo lugar, porque gobierno democrático no es sinónimo de crisis de autoridad, sino todo lo contrario, en la medida que goza de mayor legitimidad y, en consecuencia, del apoyo popular. Para dicho autor, la inseguridad se vincula más con el cambio social que con el político, razón por la que, para resolver dicho problema, habría que incidir en mayor medida en aspectos sociológicos.

\section{LA POLICÍA EN LAS SOCIEDADES DEMOCRÁTICAS}

Dicho lo anterior, parece llegado el momento de cerrar este análisis con la descripción de lo que ocurre con la Policía en los sistemas democráticos, en los que, curiosamente, se da una coincidencia a la hora de considerar todas las cuestiones relacionadas con la seguridad como las más prioritarias para los ciudadanos. En ese sentido, Oliva considera que la Policía constituye en las socie- 
dades modernas un aparato institucional de indudable importancia no sólo en cuanto instrumento de poder, sino también como mecanismo que coopera a la siempre difícil tarea de consolidar la democracia. En ese sentido, se puede decir que debe entenderse como parte del conjunto del sistema penal, estar al servicio de la comunidad y, sobre todo, ser un servicio democrático, tanto en su estructura como en su funcionamiento.

La diferencia fundamental con las dictaduras es que, aquí, el Estado, y por tanto sus fuerzas de seguridad, han de limitar todas sus actuaciones al imperio de la ley, quedando sometidos uno y otras a múltiples y diversos tipos de controles. La finalidad de éstos es la de evitar la corrupción y comportamientos ilegales, para lo cual es necesario contar con comisiones de control externas a la institución, independientes y permanentes, con capacidad de investigar y proponer la adopción de las medidas correctoras necesarias, algo realmente difícil si se tiene en cuenta que la propia subcultura policial tiende a exaltar la lealtad del grupo por encima de la integridad. La grandeza de la democracia para la Policía es que dispone de toda la legitimidad y apoyos sociales e institucionales para llevar a cabo su labor.

Atribuir excesivas facultades a la Policía, sin tener que someterse a los habituales controles en un sistema democrático, puede conducir a una potenciación de los rasgos característicos de lo que se ha venido en denominar Estado policía, en el que todos los ciudadanos son sospechosos por sistema para el poder y los jueces ven limitadas sus facultades de control, en favor de una mayor discrecionalidad administrativa, a la hora de interpretar el alcance de los derechos individuales de los ciudadanos.

La primera pregunta que cabría hacer es si la democracia dispone de un modelo único de Policía capaz de dar soluciones a las demandas de sus ciudadanos, cuestión de difícil respuesta si se tiene en cuenta que, desde el punto de vista organizativo y funcional, no existe ese modelo, toda vez que, como asegura Oliva (1994: 153), éstos no son más que algo "esquemáticos, y en cierto modo intemporales", cuando lo que se requiere es que sean "modelos prácticos» ubicados en contextos singulares de tiempo y espacio, acomodados a la cultura e idiosincrasia de la comunidad a la que sirven.

$\mathrm{Si}$, como ya es universalmente aceptado, es la sociedad la que siempre modela al aparato policial que la sirve, y no al contrario, como durante mucho tiempo se pensó, parece evidente, entonces, que en un sistema democrático y plural la Policía no pueda cumplir de manera satisfactoria las funciones que se le confían si no dispone del apoyo y colaboración de la sociedad. Como afirma Vignola (1983: 145), "la Policia, antes que ser el brazo secular de los tribunales o actuar en nombre de una autoridad gubernativa dirigista y represiva, debe permanecer al servicio de la comunidad y tener como misión esencial la de garantizar la evolución normal de la misma».

En base a lo expuesto, parece oportuno hablar no de un número restringido de sistemas policiales, sino de grandes rasgos definitorios de los mismos, como lo demuestra el hecho de que, ni siquiera dentro de Europa, se encuen- 
tren más de dos sistemas que se puedan considerar similares, funcional u organizativamente. De los aspectos comunes a casi todos ellos cabría destacar los siguientes.

En primer lugar, y respecto a la consideración anteriormente expuesta, se ha producido una importante transformación en lo que se refiere a selección de altos responsables en la Policía, pues el tradicional trasvase de militares ha dado paso a personal profesional de los Cuerpos y, en lo que respecta a la cabeza visible de los mismos, a personas ajenas a la institución. Además, ni siquiera en los regímenes democráticos la Policía escapa a las acusaciones de politización - por connivencia con el poder ejecutivo- ni a las tensiones con el poder judicial.

En cuanto a la primera de ellas, entra dentro de la tendencia que todos los gobiernos manifiestan a favor de extender su influencia y control sobre los otros poderes clásicos y sobre la sociedad en su conjunto, utilizando para ello todos los medios a su alcance, incluida la Policía, para lo cual procura seleccionar, promocionar y situar en la cabeza de la misma a personas presuntamente afines a su ideología. Mayor trascendencia pública suelen presentar los enfrentamientos entre jueces y policías, pues aunque la teoría jurídica democrática establece una relación de subordinación de la Policía ante la justicia, lo cierto es que, en la práctica, aquélla suele actuar en muchos casos al margen de ésta. Mientras los jueces acusan a los policías de actuar de manera expeditiva y en muchos casos al margen de la ley, éstos tachan a aquéllos de laxitud en la represión de la delincuencia.

Lo que parece evidente es que, además de una clara tendencia a la autonomía - el descontrol de los aparatos de seguridad se trata de justificar no sólo por largas tradiciones históricas, sino por la extendida creencia de que un exceso de controles legales impide conseguir niveles óptimos de eficacia a la hora de combatir las causas de inseguridad--, la Policía goza de un margen muy estimable de discrecionalidad, con consecuencias trascendentales, sobre todo en el ámbito penal, en la medida que no se persiguen todos los delitos con la misma intensidad ni se adoptan iguales medidas en supuestos aparentemente semejantes.

En algunos casos, como recientemente en nuestro país, se pretende resolver el conflicto entre los Ministerios de Justicia - garante de las libertades-y del Interior, responsable de mantener la seguridad, con la fusión de ambos departamentos, lo que no hace sino falsear el debate, en la medida que no pueden existir políticas divergentes al corresponder la responsabilidad final al Gobierno en su conjunto. La permanente desconfranza y enfrentamientos entre los poderes ejecutivo y judicial —¿ ¿se puede hablar de intereses contrapuestos?-, manifestados a través de los que llevan a cabo jueces y policías, lo que viene a demostrar es el papel instrumental que éstos juegan en muchos casos.

Para tratar de ir buscando alguna solución a ese distanciamiento, fruto en la mayor parte de las ocasiones del desconocimiento institucional, aparte de cumplir de manera escrupulosa con la normativa vigente o establecer de mane- 
ra más nítida los niveles de relación entre ambos colectivos, parecería oportuno integrar dentro de los planes de estudio de las carreras judicial y fiscal sesiones dedicadas a impartir conocimientos sobre la realidad del aparato policial que se va a poner bajo sus órdenes.

Otros aspectos a considerar serían, por una parte, la crisis en que ha entrado la tradicional figura del agente generalista - capaz de enfrentarse o resolver cualquier tipo de situación- en favor del especialista, mejor dispuesto a adaptarse a los rápidos cambios sociales y tecnológicos que se producen. Por otra, en un análisis de esta naturaleza no puede pasarse por alto las consecuencias que se han derivado de la introducción del sindicalismo en la Policía, en la medida que conseguir ese derecho ha sido un proceso largo y conflictivo, de tal manera que todavía hoy existen múltiples problemas en los distintos países -incluso en los democráticos - a la hora de dar respuesta a las demandas de los agentes.

Más novedosa resulta la incorporación de la mujer, pues su entrada ha supuesto no sólo mejorar las posibilidades de conseguir mejores niveles de eficiencia en el servicio - sobre todo para hacer frente a ciertas tipologías de delitos o recabar información en determinados ambientes-, sino facilitar la comprensión por parte del sector femenino de la población del papel de la misma en una sociedad democrática e igualitaria, al tiempo que abre una nueva época institucional en la que los tradicionales valores masculinos van a ser puestos en cuestión por el cada vez más importante número de mujeres que acceden a la profesión.

La prolongación del ciclo vital de la población, con un porcentaje muy estimable de personas que requieren atenciones específicas; una nueva cultura del ocio, que genera permanentes flujos de población de unas zonas o países a otros; la siempre permanente revolución tecnológica, con la exigencia de una puesta al día del personal encargado de utilizar esos nuevos medios, son sólo algunas de las cuestiones más visibles del cambio. Es interesante, respecto al cada vez mayor trato que se tiene con personas pertenecientes a minorías étnicas, la tendencia observada ya en muchas Policías a reclutar nuevos agentes entre miembros de las mismas.

Loubet (1992: 42) descubre en los regímenes democráticos un predominio de las motivaciones societales sobre las políticas, por lo que el papel de la información es mucho menor que en los regímenes autoritarios, al poder expresarse libremente todas las demandas societales; en tanto Martín (1990: 188) entiende que la Policía en una democracia sólo tiene sentido y justificación en función de su concepción como servicio público, no como una finalidad en sí misma ni como una herramienta de control al servicio de intereses minoritarios. Ello exige: mayor nivel de formación, mejores estructuras, más medios y, sobre todo, una concepción diferente de lo que es la Policía para los ciudadanos, con el fin de llegar a ser un "grupo profesional especializado en la mejora de la calidad de vida dentro de una sociedad desarrollada".

De cualquier manera, en el mundo occidental ya nadie pone en duda que la Administración civil es la única que puede encargarse del orden público 
—está sometida a Derecho en todas sus actuaciones-y que no se le permite cualquier medio para conseguir los fines, por muy justos que sean. La Policía se convierte, así, en un servicio público de protección, próximo a los ciudadanos, cuyos objetivos generales comparte y que coopera en la formulación de sus políticas y en el control de sus actividades, basada en el principio de que los derechos y libertades de los ciudadanos son intocables, en la medida que constituyen el fin último de la política, y que nada justifica su eliminación o cercenamiento.

La experiencia demuestra que la actividad de la Policía se mueve, en general, por debajo de los estándares de legalidad en materia de libertades y garantías; sin embargo, es necesario recordar que las decisiones que avalan ese tipo de comportamientos suelen tomarse en centros de poder político no corporativos y por intereses a veces bien distintos de los que inspiran las actuaciones profesionales de los policías. Si es cierto que existe una mayor predisposición de los agentes hacia las tareas represivas que hacia las preventivas, la progresiva implantación de modelos de Policía de proximidad lo que viene, entre otras cosas, es a poner en cuestión esa tradición histórica.

En un sistema democrático, el mantenimiento del orden debe entenderse como un equilibrio entre las diferentes fuerzas sociales y el establecimiento de cauces de resolución de los conflictos inherentes a toda sociedad compleja, lo que implica enfrentarse a problemas en situaciones de permanente conflictividad y la prevención de los mismos. Es por eso que Martín (1990: 180) considera que el policía, sobre todo en situaciones de crisis, es un profesional que está en buena disposición para reducir o evitar las consecuencias de la desintegración social, para lo cual ha de usar de todos los medios a su alcance de cara a generar en esa misma sociedad el civismo necesario para su normal funcionamiento.

Ése es el planteamiento de A. Reiss (1983: 194) cuando afirma que el trabajo de la Policía es problema de todos los ciudadanos, ya que es "el único servicio de nuestras comunidades para las ocasiones críticas", cuestión, por cierto, nada superflua si se tiene en cuenta que lleva directamente al debate de hasta dónde debe llegar la actuación de la Policía. Al mismo tiempo, se pone de manifiesto la necesidad de que los miembros de estas instituciones comprendan que su trabajo tiene generalmente como marco la incertidumbre, el delito y la crisis, pues, parafraseando a M. Duverger, "cuando las gentes no creen ya en sistemas de valores, la sociedad no se mantiene más que por la policia».

En el Estado moderno, ese rol de la Policía se manifiesta al participar tanto en las tareas de prevención general y especial y cooperar con las demás fuerzas productivas en la consecución de fines esenciales para el mismo, como en la más específica de lucha contra la criminalidad, faceta ésta en la que hay que tener en cuenta hoy en día no sólo el factor humano - eslabón de transmisión insustituible a la hora de explotar nuevas y complicadas tecnologías-, sino la colaboración entre Estados, de cara a promover actuaciones globales contra una delincuencia cada vez más universalizada.

A la tradicional idea de represión viene a sumarse, en la actualidad, la de prevención, lo que no es más que el comienzo de una verdadera profesionaliza- 
ción de estas instituciones. La exigencia es, pues, conseguir una Policía organizada con criterios modernos de profesionalidad y eficiencia. Respecto a las dificultades para adaptarse a ese nuevo rol, Susini (1982) justifica su afirmación de que "los policías son víctimas de un clima evolutivo que los sobrepasa", en el que el Derecho llega tarde para afrontar y regular las tensiones sociales, cuando muchas de ellas ya han cristalizado y se han radicalizado.

En definitiva, puede decirse, con Oliva (1994: 153), que la seguridad ciudadana en un régimen democrático supone la combinación correcta y ajustada de diversos medios: vigilancia policial; preparación técnica para combatir la delincuencia; sistema penitenciario adecuado a los principios de reinserción, y una Administración de Justicia ágil, capaz de dar respuestas rápidas a las demandas ciudadanas. Sin embargo, hay que tener en cuenta que, aparte de que el grado de complejidad de la sociedad actual hace inviable un sistema policial aislado del resto de la sociedad, la interrelación entre Policía y comunidad difícilmente llegará a cotas ideales dada la tradicional desconfianza de las personas hacia toda representación de poder o autoridad. Para él, la organización policial en la actualidad sería un conjunto formado por "cinco unidades interrelacionadas" - ambiente de la organización; tecnología organizacional; estructura; procesos de administración y de toma de decisiones-, que constituirían un "modelo sistémico» en el que el procesamiento de información y el respeto a la estructura se retroalimentan de manera constante.

En la década de los ochenta se confrontaron dos modelos bien diferentes, representativos de dos sociedades consideradas de las de mayor desarrollo económico. Frente al modelo rígido norteamericano, no integrado en la sociedad y visto con desconfianza por la población, lo que provoca escasa colaboración ciudadana y un bajo índice de denuncias, se presentaba el japonés, como ejemplo de participación de los ciudadanos en tareas de vigilancia permanente a efectos de prevenir la delincuencia, para lo cual la Policía dispone de un censo de familias de la comunidad que tiene bajo su control a las que visita de forma periódica, para informarse de los problemas que padecen - sociales, económicos, psicológicos, etc.- y tratar de resolverlos, algo que se considera eficaz para lograr su confianza y posterior colaboración ciudadana. Si bien es cierto que conoció descensos importantes en los niveles de delincuencia, se descubrió un grave problema como era la multiplicación del control social, primer paso hacia una sociedad que J. M.a Rico denomina de "mirada permanente", en la que todos desconfían de todos y cualquiera puede convertirse en policía de su vecino.

En la democracia los responsables policiales, además de tratar de conseguir los objetivos fijados en los planes de seguridad que se le encomiendan, persiguen transmitir a la ciudadanía una imagen de eficiencia que sea recibida por ésta en condiciones adecuadas. Es así cómo, en los últimos tiempos, han proliferado los gabinetes de imagen y relaciones informativas dentro de las organizaciones, como un eslabón más en el cumplimiento de su misión. El problema se plantea a la hora de establecer el marco de relación entre el público y la Policía, al ser frecuentes las contradicciones e interferencias entre ambos. 


\section{LA IMAGEN PÚBLICA DE LA POLICÍA}

Hasta épocas bien recientes, el policía no valoraba suficientemente que eran los ciudadanos los que le permitían desarrollar su trabajo, sino que prefería que éstos permaneciesen al margen de sus actividades, lo que generaba un enfrentamiento de posiciones en el que eran las dos partes las que salían perjudicadas. En efecto, mientras la Policía juzgaba a la sociedad en función de las potenciales ayudas que pudiese recibir a la hora de resolver sus investigaciones, los ciudadanos trazaban una imagen de aquélla en base a la experiencia extraída de sus relaciones con la misma, bien fuese de manera directa o a través de terceras personas o de la que transmitiesen los medios de comunicación.

De la importancia que para la Policía tiene su imagen es esclarecedora la, en ese sentido premonitoria, afirmación de Fouché recogida por Loubet (1992: 84), cuando, al referirse a la misma, insistía en que se "administraba más por el imperio de las representaciones y de la aprehensión que por la comprensión y empleo de medios coercitivos". A la hora de hablar de imagen y prestigio de la Policía existe una contradicción entre la presunta falta de prestigio y mala imagen de la profesión y lo que resulta de las encuestas que periódicamente se efectúan, como se pone de manifiesto a continuación.

Valoración de instituciones y organizaciones

(Medias: escala 1, muy mal; 10, muy bien)

\begin{tabular}{|c|c|c|c|}
\hline Instituciones & Febrero 92 & Diciembre 93 & Abril 96 \\
\hline Parlamento & 5,1 & 5,4 & 5,5 \\
\hline 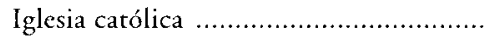 & 5,3 & 5,7 & 5,7 \\
\hline 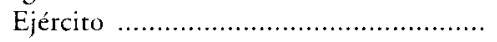 & 4,9 & 5,4 & 5,1 \\
\hline Partidos políticos ................................. & 4,1 & 4,1 & 4,4 \\
\hline 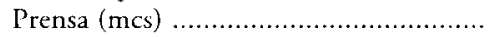 & 6,4 & 5,9 & 6,5 \\
\hline Fuerzas de Seguridad del Estado ............ & 6,3 & 6,2 & 6,6 \\
\hline Sindicatos & 5,1 & 4,9 & 5,2 \\
\hline 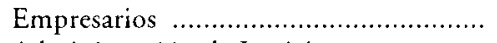 & 4,8 & $*$ & 5,5 \\
\hline Administración de Justicia ...................... & 4,5 & 4,7 & 4,9 \\
\hline 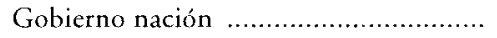 & 4,9 & 4,5 & * \\
\hline Gobierno Comunidad Autónoma ......... & 5,0 & 4,9 & * \\
\hline Ayuntamiento de su ciudad .................. & 5,4 & 5,2 & * \\
\hline
\end{tabular}

FUENTE: CIS. Series: 09601 a 09602.

De la observación del cuadro, en el que se recoge la valoración de doce instituciones suficientemente representativas, se desprende que, a lo largo del período analizado, las Fuerzas de Seguridad del Estado ocupan el primer lugar, salvo en 1992, que se ven sobrepasadas ligeramente por los medios de comunicación, con los que comparten prácticamente resultados y a una diferencia 
considerable del resto, lo que indica no sólo su alta consideración ante la opinión pública, sino la permanencia de la misma en el tiempo. Nótese, además, que por detrás se sitúan otras instituciones que, teóricamente, gozan de mayor valoración social pero que la terca realidad no reconoce, lo que desmiente la pretendida marginalidad de los policías.

Si de lo que se trata es de determinar el grado de simpatía hacia los grupos profesionales, los resultados siguen en general pautas similares a las referidas a las instituciones a las que pertenecen, como se desprende de los datos recogidos en el cuadro adjunto.

\section{Escala de simpatia hacia grupos profesionales}

(Medias: escala 1, "Ninguna simpatía»; 10, "Mucha simpatía»)

\begin{tabular}{|c|c|c|}
\hline Grupos profesionales & Diciembre 93 & Diciembre 94 \\
\hline 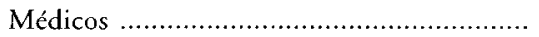 & 6,8 & 6,9 \\
\hline 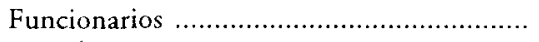 & 5,4 & 5,1 \\
\hline 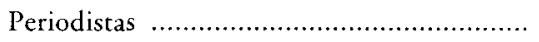 & 5,9 & 6,2 \\
\hline 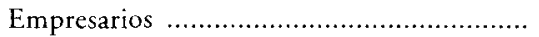 & 5,2 & 5,3 \\
\hline 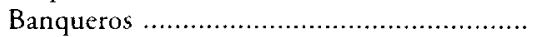 & 4,3 & 4,0 \\
\hline 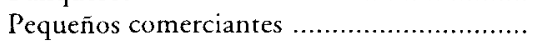 & 7,0 & 7,4 \\
\hline 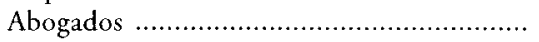 & 5,6 & 5,5 \\
\hline Jueces & 5,3 & 5,2 \\
\hline 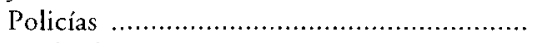 & 6,2 & 6,1 \\
\hline 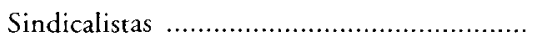 & 4,9 & 4,6 \\
\hline 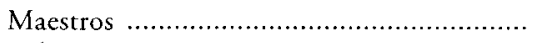 & 7,0 & 7,1 \\
\hline 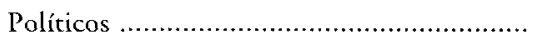 & 4,0 & 3,2 \\
\hline Militares & 5,6 & 4,8 \\
\hline 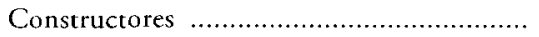 & 5,4 & 5,4 \\
\hline
\end{tabular}

FUENTE: CIS. T/14. Series: 14201 hasta 14214.

De nuevo, policías y periodistas son valorados de manera casi idéntica, si bien en este caso son superados por otros profesionales cuya dedicación se vincula tradicionalmente más con valores vocacionales que ocupacionales, como es el caso de médicos y maestros, llamando la atención la elevada simpatía que suscita la actividad de los pequeños comerciantes, sobre todo si se compara con empresarios, banqueros o constructores. Resaltar, asimismo, cómo la actividad policial, tan estrechamente relacionada con la Administración de Justicia y los jueces, resulta siempre mejor valorada que la de éstos, lo que viene a desmentir determinados planteamientos que tienen que ver más con posiciones de determinadas élites que con la realidad social que ponen de manifiesto las encuestas.

En este campo de la comunicación, una de las cuestiones más sensibles es, sin duda, la que se refiere a las relaciones entre Policía y medios de comunicación, sobre todo cuando éstos ejercen su función de control informal de las instituciones, del poder en general y de la Policía en particular. A pesar de que 
ambas partes coinciden en reconocer la importancia que tiene la información en todo lo relacionado con la seguridad, dicha relación suele acabar siendo bastante conflictiva; de ahí que, por ejemplo, en Alemania una resolución de la Conferencia de Ministros del Interior (1982) relativa a principios generales de comportamiento entre Policía y prensa estableciese: "En el campo de tensión, entre la actividad periodistica y la policial, puede llegarse a situaciones en las que cada una de las partes se puede sentir obstruida por la otra." Ello no obsta para que, en muchas ocasiones, los dos actores se necesiten mutuamente y pasen del enfrentamiento a un partenariado más o menos evidente.

Si los media suelen ser, además de fuente informativa para la Policía, instrumentos eficaces en su labor de intermediación con el público - a través de campañas de prevención o divulgación, de localización de testigos o difusión de datos de sospechosos-, aquélla les suministra información que los medios no podrían obtener por otras fuentes, de tal manera que el partenariado será más armónico cuanto mayor equilibrio exista en dicho intercambio. No obstante, lo habitual son las reticencias mutuas, de tal forma que mientras los medios se quejan de que la Policía no facilita su labor, a causa del tan manido secreto profesional, y le recuerdan la necesidad de preservar las fuentes de sus informaciones - son frecuentes las acusaciones de presiones sobre ellos, en especial en períodos de tensión política-, ésta les acusa de caer con demasiada facilidad en el sensacionalismo y la falta de rigor ante hechos de gran trascendencia social, e incluso de malograr determinados servicios al poner en alerta a los presuntos culpables.

Loubet (1992: 128) ha intentado sistematizar toda esta problemática en base a lo que denomina modelo de las $4 \mathrm{P}$, a través del estudio de las interacciones que se producen entre los cuatro elementos siguientes: Policía-PrensaPúblico-Poder político. Lo realmente paradójico del tema es que, aunque el ciudadano no suele tener muchas esperanzas respecto a la capacidad de la Policía para resolver los problemas de seguridad - suele traspasar responsabilidades a otras instituciones: gobierno, jueces, sistema penitenciario, etc.-, sigue confiando en ella, como se ha puesto de manifiesto anteriormente.

Una cuestión que merecería por sí sola un estudio monográfico es la que se refiere al vertiginoso desarrollo que, en los últimos tiempos, ha sufrido el sector de la seguridad privada, toda vez que la seguridad — al igual que la sanidad- se está convirtiendo en las sociedades modernas en un bien de consumo, lo que, frente a las cada vez mayores demandas de los ciudadanos, hace que aparezca un sector económicamente atractivo para la iniciativa privada. Se hace necesaria, pues, una racionalización de la Policía, si no se quiere caminar hacia una progresiva privatización del servicio, de la que se acabarían beneficiando las clases más favorecidas.

De cualquier manera, se puede concluir, con López Garrido (1987: 169), que la estabilidad de un sistema político depende en buena medida de lo que se denomina "fidelidad de la policía" y que, además, dependiendo de la conducta que observe respecto del ciudadano, puede ser un importante medio de 
integración o desintegración social. Una Policía con una formación más en consonancia con los valores democráticos dominantes en el sistema constitucional, y sin duda en el sistema social, es un instrumento adecuado para hacer crecer una «cultura de participación». En ese sentido, como punto de partida no sería vano retomar los principios recogidos en el Código de conducta para funcionarios encargados de hacer cumplir la ley de las Naciones Unidas y la Declaración sobre la Policía del Consejo de Europa, ambos de 1979, verdadero código deontológico para una Policía en una sociedad democrática.

\section{BIBLIOGRAFÍA}

BALL13E, Manuel (1983): Orden público y militarismo en la España constitucional (1812-1983), Alianza Universidad, Madrid.

BARIETTA, Giacomo (1992): "Evolución de la imagen de la policía y nuevos condicionantes", Harlax, núm. 6, pp. 163 y ss

BAyl.F, David H. (1985): Patterns of policing, New Brunswick, NJ.

Gi.tizAL, J.-J. (1985): Le désordre policier, Edit. PUF, París.

HERZBERG, H. U. (1994): «Constitución de una policía democrática en un nuevo Estado federal: el Estado de Sajoniam, Harlax, núm. 10, pp. 7 y ss.

JAR, Gonzalo (1997): La mujer en la Policia y las Fuerzas Armadas. Especial referencia a la Guardia Civil, Instituto de la Mujer, Madrid.

- Policia y Sociedad, Estudios de Criminología II, Universidad de Castilla-La Mancha (en impresión).

Laplirre, J. W. (1973): Analyse des sistèmes politiques, París.

LÓP. G GRrid), Diego (1987): El aparato policial en España, Edit. Ariel, Barcelona.

Loubet dei. Bayte, J.-L. (1992): La police. Approche socio-politique, Edit. Montchrestien, París.

Traducción al castellano en Edit. Acento, Colección Flash, núm. 103, 1988.

- (1996): «Du maintien de l'ordre en France», Revue International de Criminologie et de Police Technique, núm. 3, Ginebra.

MARTIN, Manuel (1991): La profesión de policía, Edit. CIS-Siglo XXI, Madrid.

Oliva Gil, José (1994): "Policía y democracia”, Harlax, núm. 9, pp. 145 y ss.

REIss, Albert: "Policía y Comunidad», en J. M. a Rico (1983: 186-210).

Rico, J. M.a (1983): Policía y sociedad democrática, Alianza Universidad, Madrid.

SAUSSAILS, B. des (1972): La machine policière, París.

S7ABO, D. (1982): La policia y la sociedad: Imágenes y realidades, I Seminario Internacional sobre la Policía, Vitoria-Gasteiz.

Viginol.A: «La administración de los servicios de policia», en J. M.a Rico (1983: pp. 145-165).

\section{ABSTRACT}

Taking a historical-political approach which departs from the traditional juridical focus of the hitherto limited number of studies on the police in Spain, this paper traces the historical evolution of this institution and attempts to define its potential role in $21^{\text {s }}$ century society. 